\title{
Maintaining Social Sustainability through the Boundary Formation of Sacred Spaces in Moslem Dwellings
}

\author{
Samsu Hendra Siwi ${ }^{1}$, Yandi Andri Yatmo ${ }^{1 *}$, Paramita Atmodiwirjo ${ }^{1}$ \\ ${ }^{1}$ Department of Architecture, Faculty of Engineering, Universitas Indonesia, Kampus UI Depok, Depok 16424, \\ Indonesia
}

\begin{abstract}
This paper addresses the issue of social sustainability in the daily spatial practices in dwellings. In particular, it discusses the establishment of sacred spaces in the everyday activities of Moslems in their dwellings, as manifested through the boundaries between clean and dirty zones related to religious rituals. The study employed a qualitative approach and the use of a case study as the method. The case study consists of six Moslem dwellings in urban areas, using in-depth interviews and observations to obtain data about the activities and behaviors of the dwellers. The boundaries between clean and dirty zones were found to be established based on the journey of footwear in the house. The formation of these boundaries could be considered a mechanism for maintaining the place's sustainability - a way to maintain the cultural identity of Moslems in their dwellings. The sustainability of sacred places was established through social agreement on the use of spaces and the boundaries defined for temporary spaces.
\end{abstract}

Keywords: Moslem dwelling; Sacred spaces; Social sustainability; Spatial agreement; Temporary

\section{Introduction}

Sustainable development goals are defined by four inseparable sustainability aspects: environmental, economic, legal, and social sustainability (Suwartha et al., 2018). One of the goals of social sustainability is the achievement of well-being and quality of life through connection between the built environment and social experience (Vallance et al., 2011). The social sustainability goal will not succeed without the community, so it is important to understand the role of the community in maintaining sustainability and promoting wellbeing in the daily living environment.

Social sustainability emphasizes the preservation of social values, cultural traditions, and ways of life (Vallance et al., 2011). Culture interacts with cultural identity to influence both individual and collective values (Gudykunst et al., 1996). Cultural identity is an individual's sense of self that comes from the formal or informal membership of a group "that transmits and instils knowledge, beliefs, values, attitudes, traditions, and ways of life" (Jameson, 2007). It is important to consider cultural identity in order to understand a community's values (Gudykunst \& Nishida, 2000). Cultural identity is important as a frame of reference for how individuals define themselves and how they respond to their social relationships (Gudykunst et al., 1996). Therefore, it is important to maintain cultural identity in order to maintain the social sustainability of a particular community.

*Corresponding author's email: yandiay@eng.ui.ac.id, Tel.: +62-21-7863504; fax: .+62-21-330343 doi: 10.14716/ijtech.v11i1.3764 
This paper addresses the issue of social sustainability as manifested in how societies maintain their cultural identities through daily spatial practices in their dwellings. Culture is built into the structure of space and place (Panjaitan, 2017). The main issue addressed in this study is how to maintain place sustainability in relation to cultural and religious practices. Specifically, the objective of this study is to explore the presence as sacred spaces within Moslem dwellings. The discussion of sacred spaces in dwellings is important because they are the medium that accommodates spiritual needs, which are ultimately related to the well-being of a dwelling's inhabitants. A sacred spaces accommodates the relationship of a person or community with "the other." The presence of a sacred spaces is an important aspect of maintaining social sustainability in the dwelling since the dwelling needs to be the place inhabitants can instill the values of life. The study of sacred space and religion continues to intersect with everyday habits and behaviors; environmental beliefs, attitudes, and practices; social mobility, hybridity, and identity; relations between private and public space; and geopolitics and territorial imaginations (Della, 2015).

The idea of sacred spaces in general, is related to divinity. In any religion, a sacred spaces in the dwelling is often associated with the existence of a particular kind of object, like an altar or a family temple. As such, a sacred spaces is often a particular place to perform a religious ritual. However, in Islam, prayer can be performed anywhere as long as the particular spatial requirements are met. For Moslems, the practice of compulsory five-timesdaily prayer means that many spaces can be considered sacred, as they may conduct their daily activities in different spaces throughout the day. The requirement for sacred spaces in Islam refers to the necessity for prayer activities to be in accordance with Islamic law, namely the requirement for cleanliness (places without najis and hadats) and an exact orientation to Kaaba. This is quite different from the concept proposed by Jackson and Henrie (2009), where the requirements of sacred spaces are to be divided into three levels: mystico-religious (related to beliefs), homeland (ancestral/homeland), and historical ties. Meanwhile, Levi and Kocher (2013) defines sacred spaces as a phenomenon of experience, behavior regulation, and aspects of identity. These broad understandings may explain various dimensions of sacred spaces; however, for the purpose of this study, we will focus on the establishment of sacred spaces as related to the requirement of cleanliness in Islamic law.

\section{Boundary Formation as a Strategy to Maintain Identity}

In establishing the concept of a sacred spaces as a space of worship, the idea of "clean" could be manifested both physically and non-physically. This study will explore how the spatial boundary formation system of clean-dirty, which might be both tangible and intangible, is established in the context of sacred spaces in dwellings. The boundary formation system may reflect the social role of inhabitants maintaining their cultural identity in their dwelling. The establishment of the boundaries of sacred spaces in the dwelling is considered an individual interpretation of the requirements for a sacred space. This paper argues that the spatial practice of fulfilling the requirement for cleanliness reflects a mechanism to maintain social sustainability-a way to maintain cultural identity through religious routine in a spatial setting.

Cultural experience is an event specifically for a group of individuals with shared beliefs, values, traditions, customs, practices, and languages (Berry and Candis, 2013). Values describes our feelings about the importance of something in our daily lives. Values are things that are considered good or desired by people in a culture (Adams, 2015). The cultural and religious experiences of communities often play a central role in determining their worldviews and the ways in which they understand their own circumstances (Halafoff 
and Clarke, 2018). Cultural values based on culture identity have a direct influence on behavior (e.g., through cultural norms and rules), but there are also indirect effects through the socialization process, when people learn individual values (Gudykunst et al., 1996). Some norms are related to politeness, such as taking shoes off at home (Adams, 2015), but one very strong influence on identity is religion (Adams, 2015). It is then possible to consider religious practices in everyday life as a way that people establish their cultural identity.

In everyday life, Moslem communities perform religious rituals, namely the five-timesdaily prayer. These prayers may be performed in mosques, which are specially dedicated for prayer, and at home. When prayer is performed at home, where the spaces also accommodate other daily activities, boundary formation to define a sacred space suitable for prayer according to Islamic law becomes important. Spatial boundaries are formed as the mechanism to regulate the use of spaces. The understanding of the spatiality of domestic activities requires a comprehension of the details of how activities are performed (Yatmo and Atmodiwirjo, 2013). In the context of everyday living spaces, the formation of architectural spaces can be established through the presence of everyday items (Yudistira et al., 2019). Therefore, the formation of boundaries can be understood by looking into the use of space and objects involved in everyday activities. In addition, the movement of inhabitants also plays an important role in relating the body to the space it occupies (Franck and Lepori, 2000). This paper attempts to examine the formation of spatial boundaries by looking into the role of everyday objects and inhabitants' movement and argues that how spatial boundaries are defined may reflect the intention to maintain a particular identity in a particular setting.

In studying boundary formation in relation to a sacred space, it is interesting to note that there might be various ways of establishing the boundaries between clean and dirtyto avoid contact with dirty matter categorized as najis. In Islamic law, clean means not najis and hadats. Najis is material dirty, and hadats is immaterial dirty (Sarwat, 2018). The repeated practices in a spatial setting could define the identity of the place (Yatmo et al., 2013). In the context of a dwelling, however, there are various repeated practices by the inhabitants in their everyday life. The practice of daily prayer carries particular "clean" requirements, which may not be needed for other routine practices. This paper attempts to identify the kinds of boundary-establishing practices necessary to define the sacred space for prayer, within the context of everyday activities of the dwelling. It offers the benefit of understanding the formation of space based on boundary establishment for cultural practice.

\section{Methods}

This study used a qualitative approach. The method employed is a case study, with the intention to explore an issue through several cases within a particular context (Cresswell and Poth, 2016). The cases consist of six dwellings inhabited by Moslem families of more than one person located in urban areas in Bekasi, Jakarta, and Surabaya. The cases were chosen to represent the behavior of the residents in relation to their religious practice. Footwear is the main object of study because its uses are related to the distinction between clean and dirty space, between sacred and non-sacred space. Particular footwear might be used to protect feet on surfaces that are considered dirty, while other footwear might be used only on surfaces that are considered clean.

In tracing the journey of footwear in the dwelling, we observed the inhabitants' behavior when putting on, taking off, and changing footwear inside in dwelling. In-depth interviews were also conducted with the inhabitants to reveal their interpretation of 
Islamic law regarding clean-dirty and how they manage to achieve cleanliness in their space for prayer. The analysis was performed by mapping the journey of the footwear in relation to the spaces. The analysis also how the transition occurs between clean and dirty zones. But, case study method is that the studies do not intend to make generalizations about boundary formation; each case reflects the uniqueness of boundary formation for the sacred space in that dwelling. The findings from the journey of footwear are analyzed to see how it becomes the basis of boundary formation and how it relates to the inhabitants' interpretation of sacred space in everyday living space.

\section{Results and Discussion}

\subsection{The Establishment of Boundaries for Sacred Places through the Journey of Footwear}

The formation of boundaries for sacred spaces in Moslem dwellings found in this study could be understood by looking at the journey of footwear throughout the spaces: from spaces outside the dwelling to spaces inside the dwelling, including the common rooms, toilets, bedrooms, and prayer rooms. The diagrams in Figures 1 and 2 illustrate the journey of footwear in the six studied dwellings. Houses 2, 3, and 4 have a mushola as a dedicated prayer room; houses 1, 5, and 6 do not have one. The residents used the bedroom and other parts of the houses for prayer. For the purpose of this analysis, the floor plans of each dwelling are abstracted into the general configuration of the main spaces in the house; thus, they do not reflect the exact spatial configuration. Each diagram shows the use of different types of footwear (shoes, slippers, barefoot) in different rooms, and the description illustrates in more detail the practice of wearing footwear in each informants families. All the informants share the same understanding that the outside world is considered dirty. Thus the footwear worn outside is exposed to najis and thus can be used for outside space only. However, they differ in the use of sandals and bare feet in different spaces.

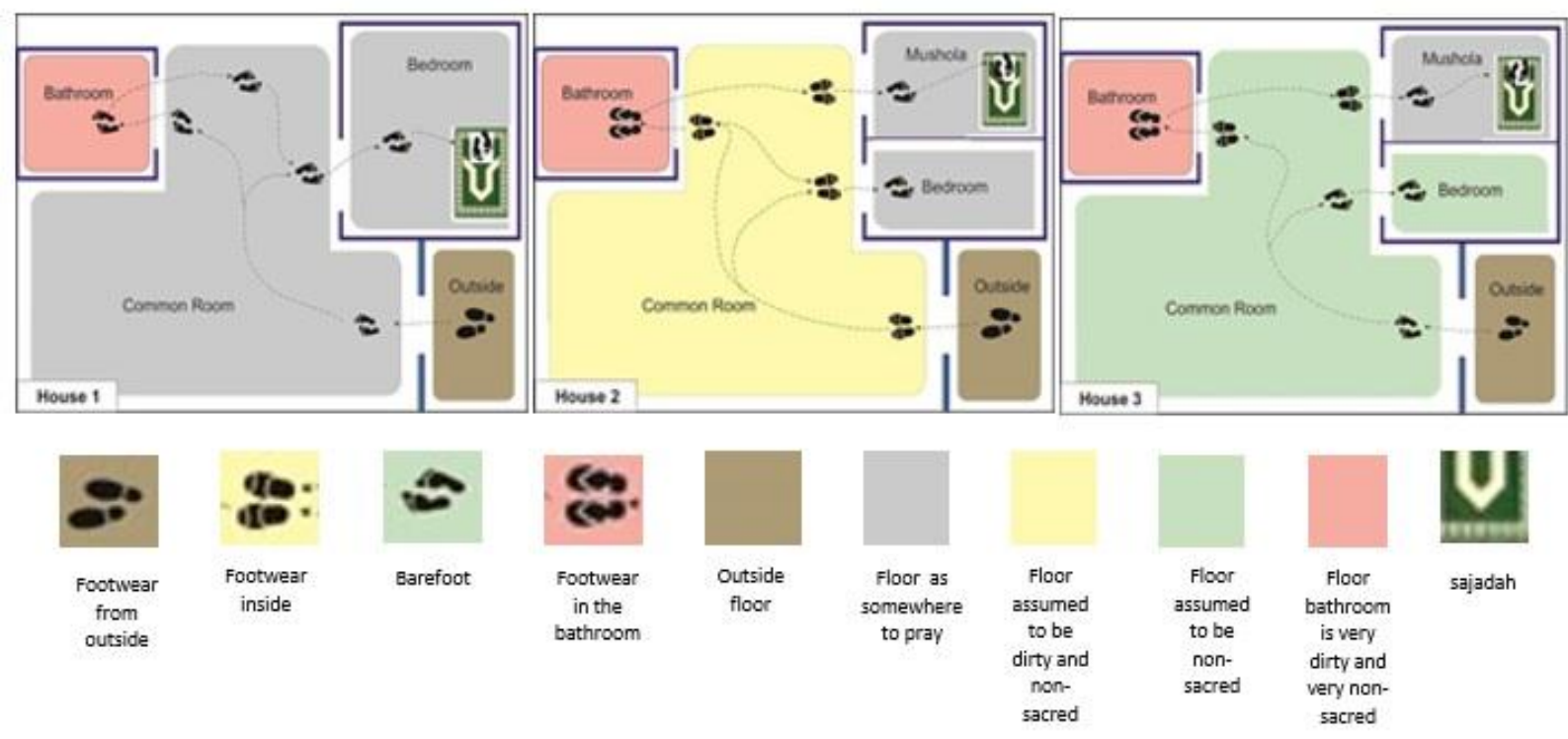

Figure 1 Journey of footwear in Houses 1, 2, 3

In House 1, the house should be entered barefoot. The floor of the house is seen as a sacred zone, so removing footwear is required. This zone could be used as a space for prayer when there are guests or family congregations on the condition that it is cleaned thoroughly to ensure that there is no najis. Activities in the toilet and wudhu are performed barefoot. As long as the feet are washed, the body is considered to not be carrying najis. After performing wudhu, shalat is performed on the sajadah in the bedroom. Thus it is considered 
a sacred space. In House 2, outside footwear is exchanged for house slippers when entering the house. Slippers are worn in all spaces except the toilet, bedroom, and prayer room. Slippers are exchanged for special toilet slippers when entering the toilet, then exchanged back to house slippers when leaving the toilet. Slippers are taken off in front of the prayer room or the bedroom. Prayer is performed using the sajadah as a sacred space. In House 3, the house should be entered barefoot. The floor of the house is a clean zone but not guaranteed to comply with the cleanliness requirement for prayer. Toilet slippers are worn when entering the toilet; after performing wudhu, they are exchanged for other slippers when moving from the front of the toilet to the mushola. These slippers are taken off in front of the mushola. Prayer is performed in the mushola using the sajadah on the floor. After prayer, slippers are no longer used for other activities in the house.

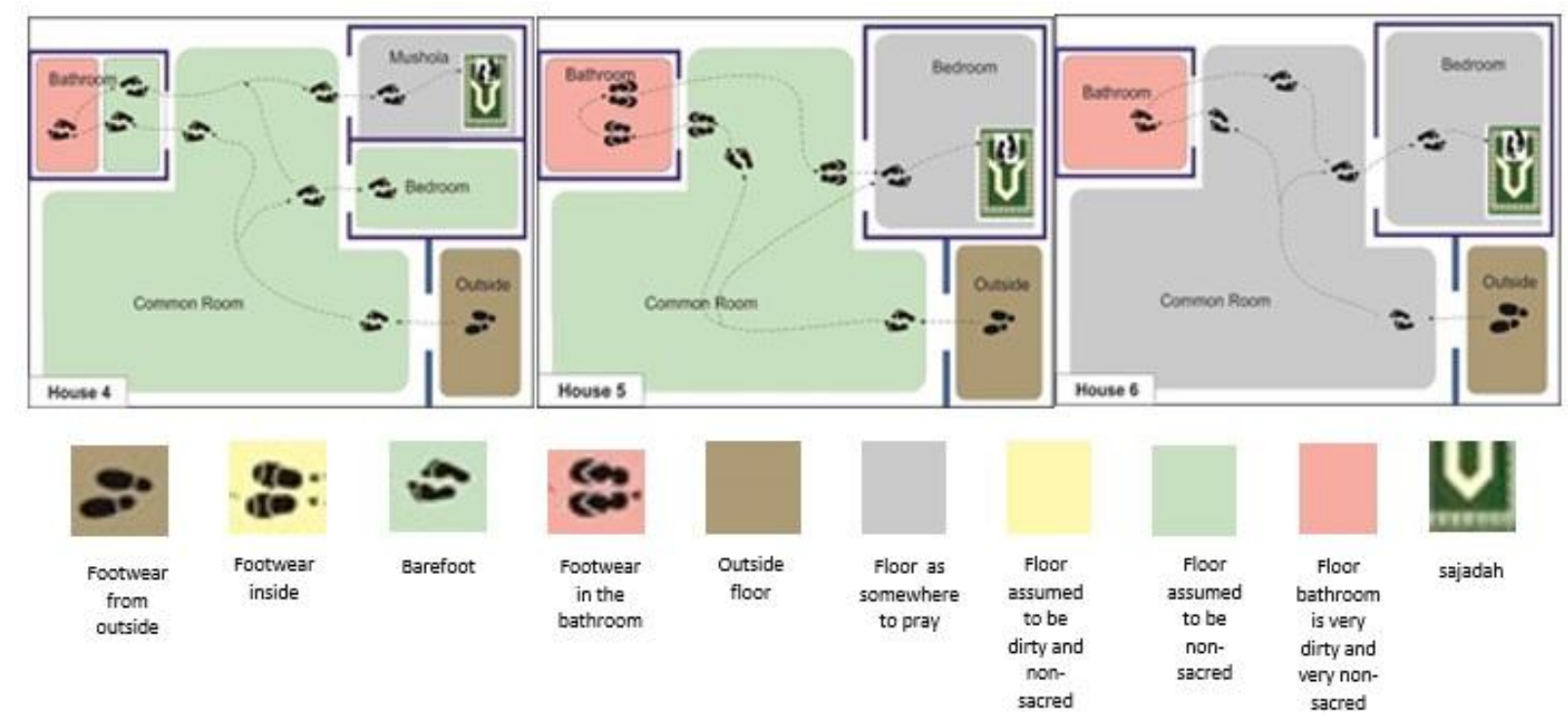

Figure 2 Journey of footwear in Houses 4, 5, 6

In Houses 4, 5, and 6, the house should be entered barefoot; the floor of the house is a sacred zone so removing footwear is required. But they differ in the use of footwear inside the house. In House 4, the activities in the toilet are performed without slippers. But in this house, there are dirty and clean zones inside the toilet. The wudhu space is the transition zone where purification activities are performed after using the closet. Movement from the toilet to the mushola for prayer is performed barefoot. In House 5, slippers are worn when entering the toilet, after leaving the toilet, and until reaching the front of the bedroom, where they are taken off. Prayer is performed inside the bedroom with the sajadah on the floor. After prayer, slippers are no longer used for other activities in the house. In House 6, similar to House 1 the house common space could be used as a space for prayer when there are guests or family congregations on the condition that it is cleaned thoroughly to ensure that there is no najis. Activities in the toilets and wudhu are performed barefoot. As long as the feet are washed, the body is considered to not be carrying najis. After performing wudhu, shalat is performed on the sajadah in the bedroom; thus, it is considered a sacred space.

A previous study by Ozaki and Lewis (2006) explored the relationship between boundaries and footwear from a socio-cultural perspective. That study suggests that culture is very influential in determining the interpretation of inside as clean and outside as dirty. In some cases in this study, all the space inside the house is considered clean, so all external footwear must be removed before entering the house and replaced with indoor footwear. Violation of this rule is considered an act of disrespect to the householder. The 
practices illustrated by the journey of footwear in the present study suggest that the exchange and removal of footwear not only relates to the distinction between inside and outside space as clean and dirty but also to the perceived level of sacredness of space in relation to prayer. The journey of footwear reflects the different levels of sacredness and the movement between those areas, as will be explained in the following section.

\subsection{Movement between the Sacred (Clean) and Non-sacred (Dirty) Areas}

Based on the illustration of six case dwellings, there are several patterns of movement throughout spaces in the house as illustrated in Figure 3 that indicate the different level of cleanliness that suggest the status of a sacred space. There are some areas in which the status of sacredness depends on the inhabitants' agreement about the space. The movement with different types of footwear, from any activities to wudhu to prayer (houses 2, 3, 5 used footwear and houses 1, 4, 6 used barefoot from bathroom) suggests the shifting status of sacredness. A mushola with a sajadah on its floor is considered a space with the highest level of cleanliness, thus the most sacred.

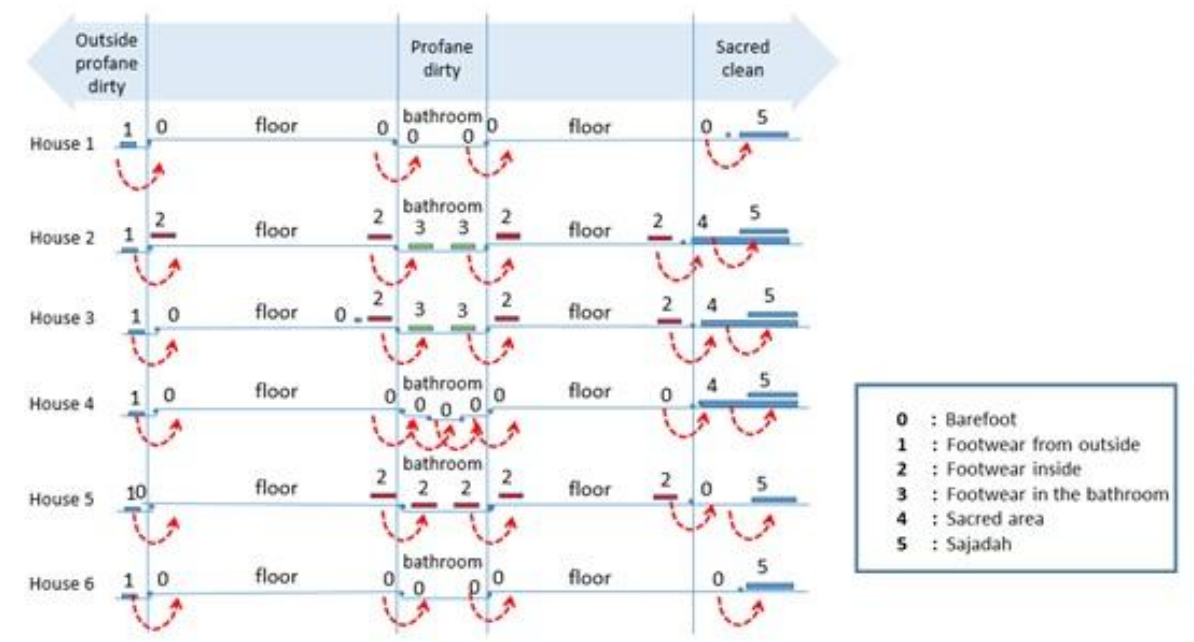

Figure 3 Movement between boundaries of sacred places

Figure 4 illustrates the formation of boundaries by different everyday objects in each of the six cases.

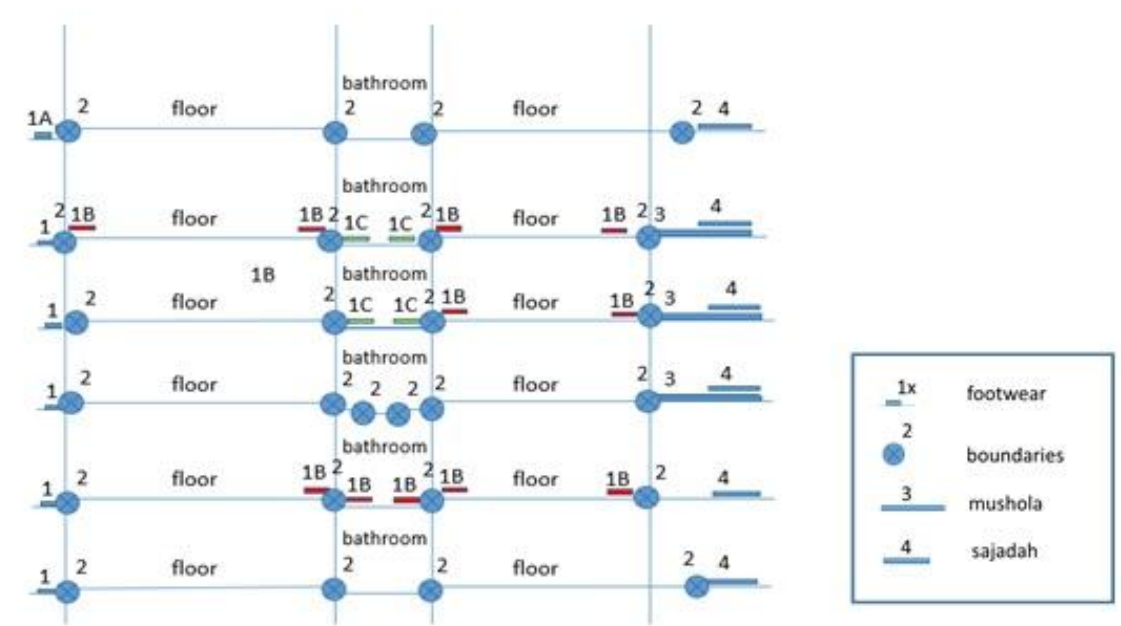

Figure 4 Formation of boundaries by footwear, spatial definition, and sajadah 
Some of the boundaries are defined by a change of footwear, which marks a change in the degree of sacredness, identified by the use of outside footwear, house slippers, bathroom slippers, and bare feet. The boundaries are defined by what happens during the movement of the inhabitants through the different spaces, such as from outside to inside and from wudhu to mushola. Another mark of sacredness is the presence of the sajadah located on the floor of a particular space, which defines the area as sacred for prayer.

Based on the description of the journey of footwear in the previous section, there are several patterns that can be identified. First, all informants agreed that the outside of the house is considered dirty, so the transition inside is marked by the removal of outdoor footwear or the change into indoor footwear. Second, the sacred space of prayer could be in the form of a permanent space-the mushola-or in the form of the temporary space, defined by a sajadah laid on the floor. Both the mushola and the sajadah are considered a sacred space that complies with the requirement of sanctity; only after performing wudhu would the person enter this space to perform prayer.

Third, the informants show different understandings of the level of cleanliness and sacredness of the other spaces in the house. In some cases, the common rooms are considered sacred spaces that can be used as a space of prayer; in others, there is no guarantee of cleanliness in the common spaces in the house, so they are still considered a space with najis. Such differences are reflected in the practice of wearing footwear or being barefoot inside the spaces in the house. Fourth, the bathroom is considered a space with much najis. In responding to this situation, some informants wear special slippers in the toilet as a way to protect the body from being exposed to the najis. Meanwhile, some informants believed that by washing their feet, they had been separated from the najis. Finally, in some cases, the movement between spaces is marked by the use of footwear after wudhu to protect the feet from being exposed to najis before reaching the sajadah or mushola. This transition will be discussed further in the following section.

\subsection{Footwear, Sajadah, and Mushola Floor: Transition between Clean and Dirty}

Further analysis of the journey of footwear in the dwelling suggests that besides the definition of clean and dirty assigned to particular spaces-such as the mushola as the permanent sacred space-the practice of wearing footwear and the laying of the sajadah on the floor play an important role in defining cleanliness or sacredness of a space.

Figure 5 illustrates the journey of footwear to sacred space in dwelling. First, wearing sandals could be considered an action to maintain sanctity to be in compliance with the religious requirements of cleanliness. As a way to protect the feet from exposure to najis, footwear serves as a transitional element. It is important to maintain a person's cleanliness when they are moving from the wudhu space to the space for prayer. Thus the footwear becomes a moving boundary between the clean feet and a floor that may contain najis. However, when the person reaches the sajadah or mushola, these sandals are removed. This point becomes the transitional boundary between the sandals and the sajadah or mushola floor.
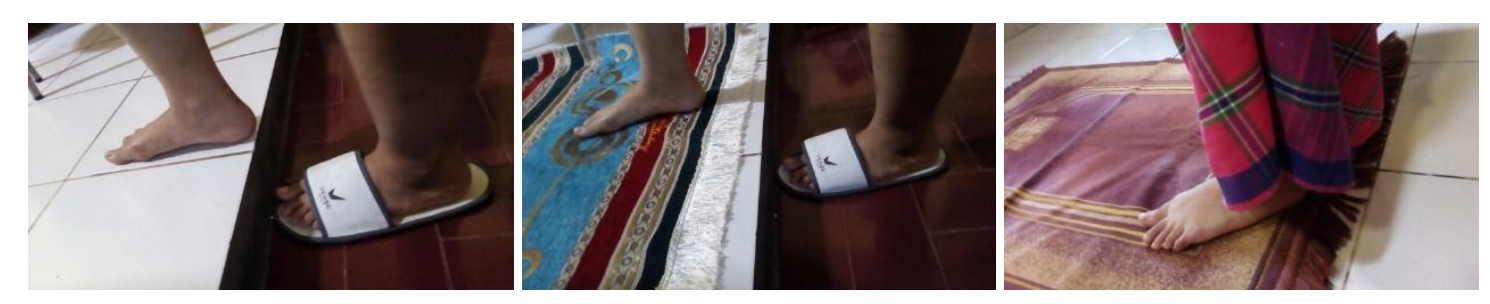

Figure 5 Sandals as transitional sacred place 
Second, the sajadah becomes a temporary sacred space created by the inhabitants, which has an important role in changing the meaning of the space. The laying of the sajadah on the floor transforms the meaning of the space-from a mundane to a sacred space for prayer. Those are seen Figure 6. Sajadah is as temporary sacred place in dwelling. Generally, the activities of prayer takes a minute; therefore, the role of the sajadah becomes a temporal definition of a sacred space. In this case, the condition of a sacred space is not permanent and absolute.
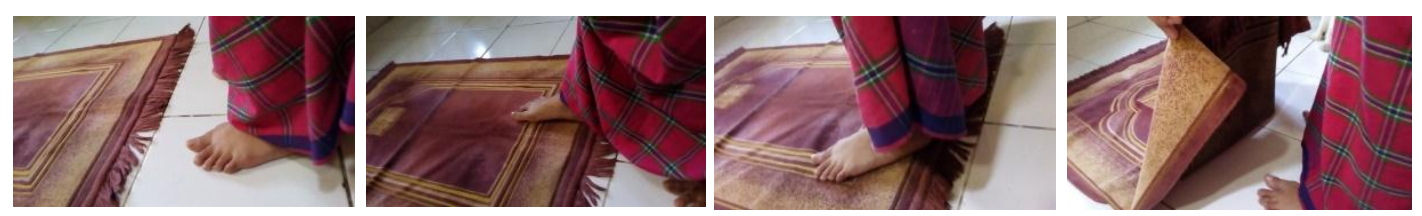

Figure 6 Sajadah as a movable and temporary sacred place

\subsection{Definition of Sacred Space through Boundary Formation}

A sacred space is produced from the relationship between a ritual and the space (Bell, 2009). The status of a sacred space stems from human mentality. Epistemologically, the status of a space is related to how the creators of the space read an event; it depends on how space occurs and functions, how the practice is related to the creator of the space, and how the underlying events and rules are implemented by the creators and users of the space (Lefebvre, 2001).

Most sacred spaces appear in the minds of humans (Henrie, 1972). The attachment to the sacred space depends on the perception of sacredness, which then forms a unique feeling of sacredness. The sacred space is always distinguished from other spaces. This is because of the existence of certain rituals which mark the value of a space's sacredness. As found in this study, the marking of sacred zones as spaces for prayer is performed through the creation of boundaries. The sacred space in the dwellings appears when constructed and interpreted as a sacred space through the establishment of boundaries.

A sajadah physically appears as a piece of cloth sized approximately $70 \mathrm{~cm} \times 100 \mathrm{~cm}$; however, when it is laid on the floor as a prayer mat, it is interpreted as a space for prostration to God. The act of laying the sajadah on the floor is an act of defining the boundary for a sacred space. It temporarily gives meaning to the floor that was previously perceived as an ordinary space, which then becomes ordinary again when the prayer is finished. A similar thing could be understood in the act of changing footwear throughout the house. The wearing of footwear defines the boundary between spaces-ones that are clean and not requiring footwear and ones that are not clean, thus requiring footwear.

Boundaries are interpreted as physical boundaries and zone separators. Boundaries contain symbolic meaning as the markers of the separation between the mundane and the sacred (Lamont and Molnár, 2002). However, the validity of boundaries involves social aspects. The practice of boundary formation and the compliance with this boundary formation system depends on the agreement of the members of the community. In the case of boundary formation of sacred spaces in Moslem dwellings, if the members of the family or outsiders do not understand the rules of this boundary formation, this person may not take off outside footwear when entering the house. In this way, this person violates the meaning of the sacred space previously established by an agreement among the inhabitants. Social agreements on value formation need routine maintenance. 


\subsection{Boundary Formation as a Way to Maintain Social Sustainability}

Social sustainability is achieved as a negotiation between physical aspects and social aspects of design; it addresses how the physical environment can support social and cultural life, with a system of community involvement. It is a process of achieving the wellbeing of society through the understanding of community needs (Seligman, 2011; Huppert and So, 2013). The process of creating sustainable spaces and achieving well-being goals need to begin with understanding what people need from their living environment (Rasouli and Kumarasuriyar, 2016). It becomes the responsibility of architecture to meet not only functional and creature comfort, but also spiritual comfort (Mockbee, 2001) in such a way that architecture could be an expression of values (Foster, 2014).

The establishment of sacred spaces in the dwelling could be seen as a way to maintain the identity of the inhabitants and to express the values related to religious belief and practice. The presence of sacred spaces reflects the cultural identity of Moslem families, as an expression of values held by the members of a Moslem society (Gudykunst and Nishida, 2000). The journey of footwear becomes a way to understand how the boundary of sacred space is constructed through the act and movement of the residents and how such boundary formation is related to the social agreement regarding the uses and sacred meaning of space. The interesting findings of this study are that the boundary formation of sacred space and the degree of sacredness is created not only by the rigid definition of space but also by the act and movement of the inhabitants and the presence of the sajadah as a temporary sacred space. This suggests that sacred space in dwellings can be present both permanently and temporally, based on the needs and desires of the inhabitants.

The establishment of the boundaries through the journey of footwear indicates how the cultural identity of its inhabitants in the dwelling. In this case, the values of sacred spaces and sanctity of spaces are achieved through the everyday acts of the inhabitants. The establishment of rules regarding sacred and non-sacred spaces and where to have footwear or be barefoot is a manifestation of the social agreement regarding inhabitants cultural and religious values. It suggests the role of the actors in an attempt to maintain the social sustainability of their living environment.

\section{Conclusions}

The agreement regarding the use of footwear in a dwelling is a way to establish the boundaries between clean and dirty areas, between sacred and non-sacred areas. The formation of these boundaries could be considered a mechanism for maintaining the space's sustainability-a way to maintain the cultural identity of Moslems in their dwellings. The sustainability of sacred spaces is established through a social agreement on the use of spaces and the boundaries defined for temporary spaces. The boundaries are established through the acts of wearing, changing, and taking off footwear; the assignment of a particular room - the mushola - as a sacred space; and the laying of the sajadah on the floor for prayer. This suggests that the boundaries of a sacred space could be established as permanent as well as transitional and temporary. The agreement of the inhabitants regarding the use of and requirements for a sacred space is a way to maintain the social sustainability of the dwelling. It indicates that sacred spaces exist as a product of a society in relation to activity and time.

\section{Acknowledgements}

This research is supported by the BPPDN scholarship grant from the Ministry of Research, Technology and Higher Education. The authors would like to thank all the 
informants for their valuable information for this study.

\section{References}

Adams, K., 2015. Culture, Identity and Cross Cultural Adjustment. Available Online at http://www.tohoku-gakuin.ac.jp/research/journal/bk2015/pdf/no01_03.pdf,

Accessed on July 6, 2019

Bell, C., 2009. Ritual Theory, Ritual Practice. Oxford: Oxford University Press

Berry, T.R., Candis, M.R., 2013. Cultural Identity and Education: A Critical Race Perspective. Educational Foundations, Volume 27, 43-64

Creswell, J.W., \& Poth, C.N., 2016. Qualitative inquiry and research design: Choosing among five approaches. Sage publications

Della, D.V., 2015. Sacred Space Unbound, Environment and Planning D: Society and Space. Virtual Issue 13

Foster, N., 2014. Architecture Is an Expression of Values, The European: das DebattenMagazin. Available Online at https://www.theeuropean.de/en/norman-foster/9114the-role-of-architecture-in-todays-

society?utm_medium=website\&utm_source=archdaily.com Accessed on July 6, 2019

Franck, K., Lepori, R.B., 2000. Architecture Inside Out. London: Wiley-Academy

Gudykunst, W.B., Nishida, T., 2000. The Influence of Culture and Strength of Cultural Identity on Individual Values in Japan and the United State. Intercultural Communication Studies, Volume 9(1), pp. 1-18

Gudykunst, W.B., Matsumoto, Y., Ting-Toomey, S., Nishida, T., Kim, K.S., Heyman, S., 1996. The Influence of Cultural Individualism-collectivism, Self Construals, and Individual Values on Communication Styles across Cultures. Human Communication Research, Volume 22(4), pp. 510-543

Huppert, F.A., So, T.T.C., 2013. Flourishing across Europe: Application of a New Conceptual Framework for Defining Well-being. Social Indicators Research, Volume 110(3), pp. 837-861

Henrie, R.L., 1972. The Perception of Sacred place: The Case of Utah and Other Sacred Places in Mormondom. Thesis of Master's, Department of Geography, Brigham Young University.Provo. Available Online at https://scholarsarchive.byu.edu/etd/4786

Halafoff, A., Clarke, M., 2018. Sacred Places and Sustainable Development. Religions, Volume 9(10), pp. 1-12

Jackson, R.H., Henrie, R., 2009. Perception of Sacred Space. Journal of Cultural Geography, Volume 3(2), pp. 94-107

Jameson, D.A., 2007. Reconceptualizing Cultural Identity and Its Role in Intercultural Business Communication. Journal of Business Communication, Volume 44(3), pp. 199235

Lefebvre, H., 2001. The Production of Space. Donald Nicholson-Smith, (trans.), Oxford, United Kingdom: Blackwell Publisher Ltd.

Levi, D., Kocher, S., 2013. Perception of Sacredness at Heritage Religious Sites. Environment and Behavior. Volume 45(7), pp. 912-930

Lamont, M., Molnár, V., 2002. The Study of Boundaries in the Social Sciences. Annual Review Sociology, Volume 28(1), pp. 167-195

Mockbee, S., 2001. His Impact on Architecture. Available Online at http://samuelmockbee.net/impact/architecture/?utm_medium=website\&utm_sourc $\mathrm{e}=$ archdaily.com. Accessed on July 6, 2019

Ozaki, R., Lewis, J.R., 2006. Boundaries and the Meaning of Social Space: A Study of Japanese House Plans. Environment and Planning D: Society and Space, Volume 24(1), pp. 91-104 
Panjaitan, T.H., 2017. Hybrid Traditional Dwellings: Sustainable Systems in the Customary House in Ngada Regency. International Journal of Technology, Volume 8(5), pp. 841850

Rasouli, H.A., Kumarasuriyar, A., 2016, The Social Dimension of Sustainability: Towards Some Definitions and Analysis. Journal of Social Science for Policy Implications, Volume 4(2), pp. 23-34

Seligman, M., 2011. Flourish. Toronto: Free Press

Sarwat, A., 2018. Terjemahan Matan Al-Ghayah wa At-Taqib: Thaharah (English trans., Sacred, Holy, Cleaness). Jakarta: Rumah Fiqih Publishing

Suwartha, N., Berawi, M.A., Surjandari, I., Zagloel, T.Y.M., Setiawan, E.A., Atmodiwiryo, P., Yatmo, Y.A., 2018. Creating a Sustainable Future through the Integration of Management, Design, and Technology. International Journal of Technology, Volume 9(8), pp. 1518-1522

Vallance, S., Perkins, H.C., Dixon, J.E., 2011. What is Social Sustainability? A Clarification of Concepts. Geoforum, Volume 42(3), pp. 342-348

Yatmo, Y.A., Atmodiwirjo, P., Paramita, K.D., 2013. Whose Waste Is It Anyway? Journal of Urban Design, Volume 18(4), pp. 534-552

Yatmo, Y.A., Atmodiwirjo, P., 2013. Spatial Strategies for Domestic Service Activities in Urban Kampung Houses. International Journal of Technology, Volume 4(1), pp. 24-33

Yudistira, F., Yatmo, Y.A., Atmodiwirjo, P., 2019. From Rigidity to Ephemerality: Architecture as a Socio-spatial Assemblage of Heterogeneous Components. A/Z ITU Journal of Faculty of Architecture, Volume 16(3), pp. 115-129 